

\section{Experimental and materials}

The process flowsheet consists of 6 steps (Fig. 1). Lithium and aluminum are first dissolved by oxalic acid in step 1 , producing a liquid stream containing $\mathrm{Li}^{+}$and $\mathrm{Al}^{3+}$ (stream 3) and a solid stream containing mixed $\mathrm{Ni}$ and $\mathrm{Co}$ oxalates (stream 4). The aluminum is removed by chemical precipitation using $\mathrm{KOH}$ (step 2) while lithium is recovered as lithium carbonate (step 3). The solid mixture of $\mathrm{NiC}_{2} \mathrm{O}_{4} \cdot 2 \mathrm{H}_{2} \mathrm{O}$ and $\mathrm{CoC}_{2} \mathrm{O}_{4} \cdot 2 \mathrm{H}_{2} \mathrm{O}$ in stream 4 is converted to mixed sulfates through an acid baking treatment (step 4). The mixed sulfates (stream 12) are dissolved in water (step 5). The cobalt in the solution is then separated as solid $\mathrm{CO}_{2} \mathrm{O}_{3}$ [4] from a solution containing $\mathrm{NiSO}_{4}$ (step 6). These steps are discussed in detail next.

\subsection{Selective dissolution by oxalic acid (step 1)}

Selective dissolution using oxalic acid was carried out in a $250 \mathrm{~mL}$ three-neck round-bottom flask with a magnetic stirrer, a heating mantle, and a reflux condenser at $95^{\circ} \mathrm{C}$ for $4 \mathrm{~h}$. The base case dissolution experiment was conducted with $3 \mathrm{~g}$ of cathode powder, and $100 \mathrm{~mL}$ of $1 \mathrm{M}$ oxalic acid, giving a solid-to-liquid ratio of $35 \mathrm{~g} / \mathrm{L}$. $1.58 \mathrm{~g}$ of $\mathrm{K}_{2} \mathrm{SO}_{3}$ was added as reducing reagent. The effects of reducing reagent concentration, temperature, and solid-to-liquid ratio on dissolution performance were investigated.

\subsection{Aluminum removal by chemical precipitation (step 2)}

As most of the aluminum was dissolved along with lithium, it had to be removed from the liquid mixture by chemical precipitation. $\mathrm{KOH}$ was added in a $20 \mathrm{~mL}$ glass vial, and the mixture was agitated with a magnetic stirrer at room temperature. After equilibration for $4 \mathrm{~h}$, the solution and the precipitated solids were separated by vacuum filtration. Collected solids were washed with DDI water and dried in a vacuum oven overnight at $70^{\circ} \mathrm{C}$.

\subsection{Lithium recovery by chemical precipitation (step 3)}

The chemical precipitation process for lithium recovery was conducted in a $100 \mathrm{~mL}$ culture bottle with a magnetic stirrer. $5 \mathrm{M}$ of $\mathrm{K}_{2} \mathrm{CO}_{3}$ was added. The mixture was placed in a water bath at $80^{\circ} \mathrm{C}$. After equilibration for $4 \mathrm{~h}$, the liquid solution and the precipitated solids were separated by vacuum filtration. Collected solids were washed with DDI water and dried in a vacuum oven overnight at $70^{\circ} \mathrm{C}$.

\subsection{Acid baking of mixed oxalates (step 4) and dissolution (step 5)}

The acid baking of mixed oxalates was conducted in a temperature controlled muffle furnace. $3 \mathrm{~g}$ of mixed $\mathrm{Ni}$ and $\mathrm{Co}$ oxalates produced from step 1 was thoroughly mixed with a specific amount of concentrated sulfuric acid $(98 \%)$ in a porcelain crucible. $1 \mathrm{~mL}$ of DDI water was also added to facilitate mixing of the slurry. Then the crucible was transferred to the muffle furnace for a 2-h thermal treatment. The powder from acid baking was dissolved in DDI water in a solid-to-liquid ratio of $50 \mathrm{~g} / \mathrm{L}$ at a temperature of $70^{\circ} \mathrm{C}$ for $3 \mathrm{~h}$. The prepared solution was used as the feed for cobalt precipitation (Stream 14).
Fig. 1 Process flowsheet for recycling LNCA cathode materials

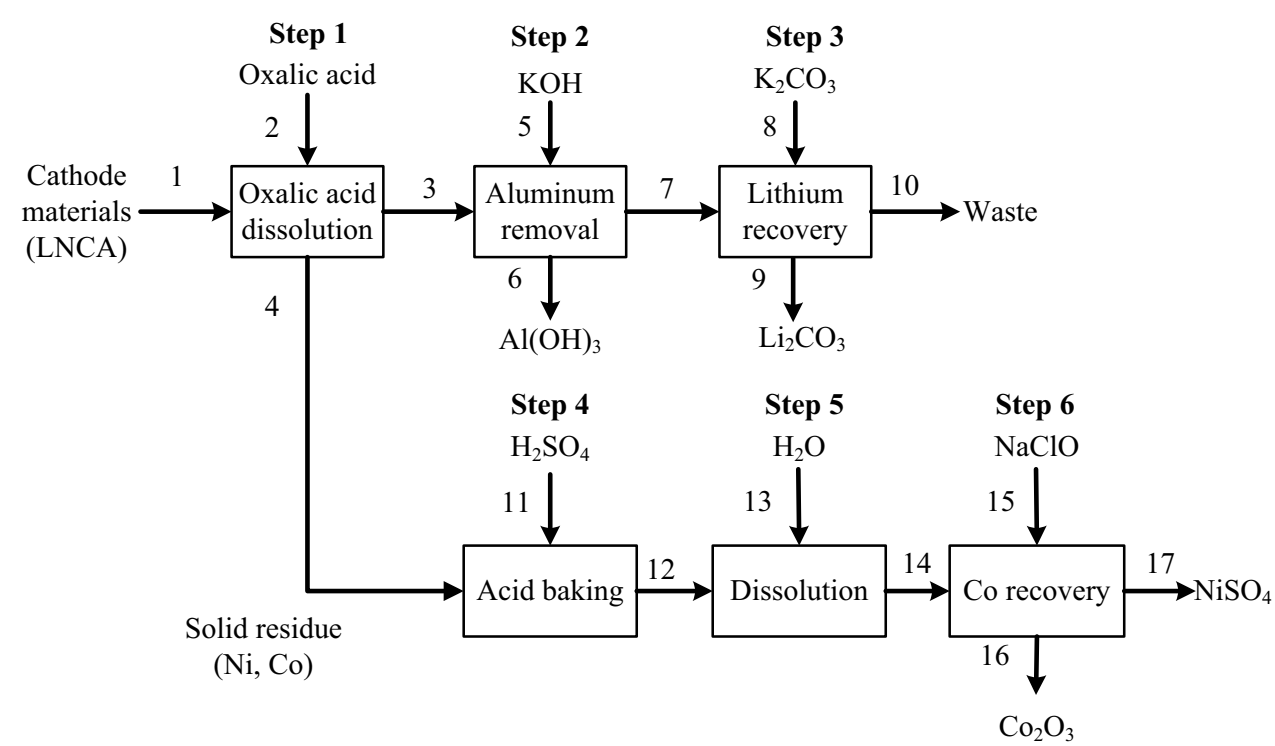




\subsection{Cobalt precipitation (step 6)}

The cobalt precipitation was conducted in a $20 \mathrm{~mL}$ glass vial with a magnetic stirrer. A specific volume of $\mathrm{NaClO}$ solution was added in $10 \mathrm{~mL}$ of feed solution. After equilibration for $4 \mathrm{~h}$, the liquid solution and the precipitated solids were separated by vacuum filtration. Collected solids were washed with DDI water and dried in a vacuum oven overnight at $70^{\circ} \mathrm{C}$.

\subsection{Analytical methods}

The $\mathrm{pH}$ of the solution was measured with a $\mathrm{pH} / \mathrm{mV}$ meter (Model Mettler- Toledo AG SevenGo2), and the metal concentrations were determined by inductively coupled plasma optical emission spectrometry (ICPOES) (Model PerkinElmer Optima 7300 DV). The standard solutions were provided by High-Purity Standards, 99.998\%, and diluted in double deionized (DDI) water with a resistivity of $18.2 \mathrm{M} \Omega \mathrm{cm}$ at room temperature. The particle morphology was examined by scanning electron microscope (SEM) (Model JEOL-JSM 7100). The chemical composition of the solids was confirmed with attenuated total reflectance Fourier-transform infrared (ATR-FTIR) spectra (Model Bruker Tensor 27 FTIR with a Bruker Platinum ATR accessory), and thermal gravimetrical analysis (TGA) (Model TA Q5000). The crystal structure was characterized by X-ray diffraction (XRD) system (Model PW1830 Philips, 2KW, Cu anode, graphite monochromator).

\section{Results and discussion}

\subsection{Selective dissolution of lithium and aluminum (step 1)}

The effects of various operating parameters including temperature $(T)$, the concentration of reducing reagent $\left(\mathrm{K}_{2} \mathrm{SO}_{3}\right)$, and solid-to-liquid feed ratio ( $\mathrm{S} / \mathrm{L}$ ratio) on this reaction with $3 \mathrm{~h}$ of dissolution are discussed next. A summary of the results is presented in Table 1. The second row shows the base case: $\mathrm{C}=1 \mathrm{M}, \mathrm{T}=95^{\circ} \mathrm{C}, \mathrm{C}_{\text {reductant }}=0.1 \mathrm{M}$, and $\mathrm{S} / \mathrm{L}=35 \mathrm{~g} / \mathrm{L}$. Considering the solubility of oxalic acid which is $1.1 \mathrm{M}$ at room temperature, the concentration of oxalic acid is selected as $1 \mathrm{M}$. The third to fifth rows show how the wt\% of metal dissolved in stream 3 change in response to the change in a single operating parameter while keeping the remaining two parameters constant at their base case values. Since only trace amounts of $\mathrm{Ni}$ and Co were dissolved in stream 3 , the following discussion
Table 1 Experimental results on the selective dissolution of lithium from cathode materials

\begin{tabular}{|c|c|c|c|c|}
\hline \multirow[t]{2}{*}{ Experimental conditions } & \multicolumn{4}{|c|}{$\begin{array}{l}\% \text { of metals being dissolved from the } \\
\text { cathode materials }\end{array}$} \\
\hline & Li (wt\%) & $\mathrm{Ni}(w \mathrm{t} \%)$ & Co (wt\%) & $\mathrm{Al}(\mathrm{wt} \%)$ \\
\hline $\begin{array}{l}\text { Base case } C_{\text {oxa }}=1 \mathrm{M}, \\
\mathrm{T}=95^{\circ} \mathrm{C}, \mathrm{S} / \mathrm{L}=35 \mathrm{~g} / \mathrm{L} \\
\mathrm{C}_{\text {reductant }}=0.1 \mathrm{M}\end{array}$ & 97.8 & 0.16 & N.D. & 91.6 \\
\hline \multicolumn{5}{|l|}{$\mathrm{CK}_{2} \mathrm{SO}_{3}(\mathrm{M})$} \\
\hline 0.05 & 87.0 & N.D. & N.D. & 73.7 \\
\hline 0.2 & 100 & 3.95 & N.D. & 97.1 \\
\hline \multicolumn{5}{|l|}{$\mathrm{T}\left({ }^{\circ} \mathrm{C}\right)$} \\
\hline 65 & 93.0 & 0.08 & N.D. & 78.8 \\
\hline 75 & 94.7 & 0.10 & N.D. & 80.1 \\
\hline 85 & 95.2 & 0.18 & N.D. & 84.2 \\
\hline \multicolumn{5}{|l|}{$\mathrm{S} / \mathrm{L}(\mathrm{g} / \mathrm{L})$} \\
\hline 30 & 98.8 & N.D. & N.D. & 96.0 \\
\hline 40 & 83.3 & N.D. & N.D. & 90.6 \\
\hline 50 & 68.0 & 2.28 & 3.09 & 46.9 \\
\hline
\end{tabular}

focuses on the concentration change of lithium and aluminum.

\subsubsection{Effects of reducing reagent concentration}

The recovery of $\mathrm{Li}$ and $\mathrm{Al}$ by selective dissolution under base case conditions with and without $\mathrm{K}_{2} \mathrm{SO}_{3}$ as reducing reagent is shown in Fig. 2. Without $\mathrm{K}_{2} \mathrm{SO}_{3}$, the dissolution of lithium and aluminum proceeded almost linearly with reaction time. With $\mathrm{K}_{2} \mathrm{SO}_{3}$, dissolution was significantly accelerated, reaching the equilibrium values within $1 \mathrm{~h}$. In this study, the reaction time would be fixed at $3 \mathrm{~h}$ for further experiments.

When the concentration of $\mathrm{K}_{2} \mathrm{SO}_{3}$ was increased to $0.2 \mathrm{M}$ from its base case value of $0.1 \mathrm{M}, 3.95 \%$ of $\mathrm{Ni}$ dissolved in the solution. This was expected because when $\mathrm{pH}$ is higher than 1.6, Ni forms a soluble complex with $\mathrm{C}_{2} \mathrm{O}_{4}{ }^{2-}$ ions present in the system. ${ }^{19}$ When the concentration of $\mathrm{K}_{2} \mathrm{SO}_{3}$ was reduced to $0.05 \mathrm{M}$, the recovery of lithium and aluminum would drop to $87.0 \%$ and $73.7 \%$ respectively, indicating that there was not enough reducing reagent to react with LNCA cathode materials.

\subsubsection{Effect of temperature}

The temperature was varied from 65 to $85^{\circ} \mathrm{C}$ while keeping other parameters at their base case values (fourth row of Table 1). The experimental results show that when the temperature was decreased from $95^{\circ} \mathrm{C}$ (base case value) to $85^{\circ} \mathrm{C}$, the lithium and aluminum recovery decreased from $97.8 \%$, and $91.6 \%$ to $95.2 \%$, and $84.2 \%$, respectively. The temperature variation shows a more substantial impact 
Fig. 2 The recovery of $\mathrm{Li}$ and $\mathrm{Al}$ in the solution a without $\mathrm{K}_{2} \mathrm{SO}_{3}$, and $\mathbf{b}$ with $\mathrm{K}_{2} \mathrm{SO}_{3}$ for different reaction times

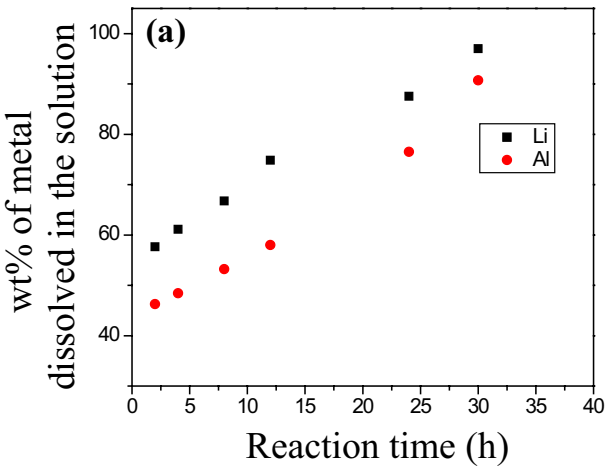

on the dissolution of aluminum than the dissolution of lithium.

\subsubsection{Effect of solid-to-liquid feed ratio}

The $S / L$ ratio was varied from 30 to $50 \mathrm{~g} / \mathrm{L}$ (fifth row of Table 1). Experimental results show that $97.8 \%$ of lithium and $91.6 \%$ of aluminum were dissolved for an $\mathrm{S} / \mathrm{L}$ ratio of $35 \mathrm{~g} / \mathrm{L}$ (base case). It dropped to $83.3 \%$ and $90.6 \%$ for an $\mathrm{S} / \mathrm{L}$ ratio of $40 \mathrm{~g} / \mathrm{L}$ and was further reduced to $68.0 \%$ and $46.9 \%$ at $50 \mathrm{~g} / \mathrm{L}$. A better recovery was achieved at the $\mathrm{S} / \mathrm{L}$ ratio of $30 \mathrm{~g} / \mathrm{L}$, giving a recovery of $98.8 \%$ for lithium and $96.0 \%$ for aluminum. Therefore, an $\mathrm{S} / \mathrm{L}$ ratio of $30 \mathrm{~g} / \mathrm{L}$, instead of the base case value, was further considered below.

\subsubsection{Solid characterization}

The solid residue needs to be characterized to investigate the chemical reaction happened during dissolution. The solid residue was collected from the selective dissolution using $1 \mathrm{M}$ of oxalic acid, and $0.1 \mathrm{M}$ of $\mathrm{K}_{2} \mathrm{SO}_{3}$, with an $\mathrm{S} / \mathrm{L}$ ratio of $30 \mathrm{~g} / \mathrm{L}$, at the temperature of $95^{\circ} \mathrm{C}$. Lithium and aluminum were found in the liquid after selective lithium dissolution as measured by ICP-OES. Nickel and cobalt were present in the solid residue in a ratio of 5.3:1. Moreover, lithium and aluminum account for $0.1 \%$ and $0.04 \%$ in the solid residue, respectively. The cathode material particles before and after selective dissolution are shown by SEM in Fig. 3. After dissolution, much smaller particles remained. The EDX mapping in Fig. 4 shows that $\mathrm{Ni}$ and $\mathrm{Co}$
Fig. 3 SEM photos of $\mathbf{a}, \mathbf{b}$ low and high magnification of cathode powder, c, $\mathbf{d}$ low and high magnification of solid residue after the selective dissolution
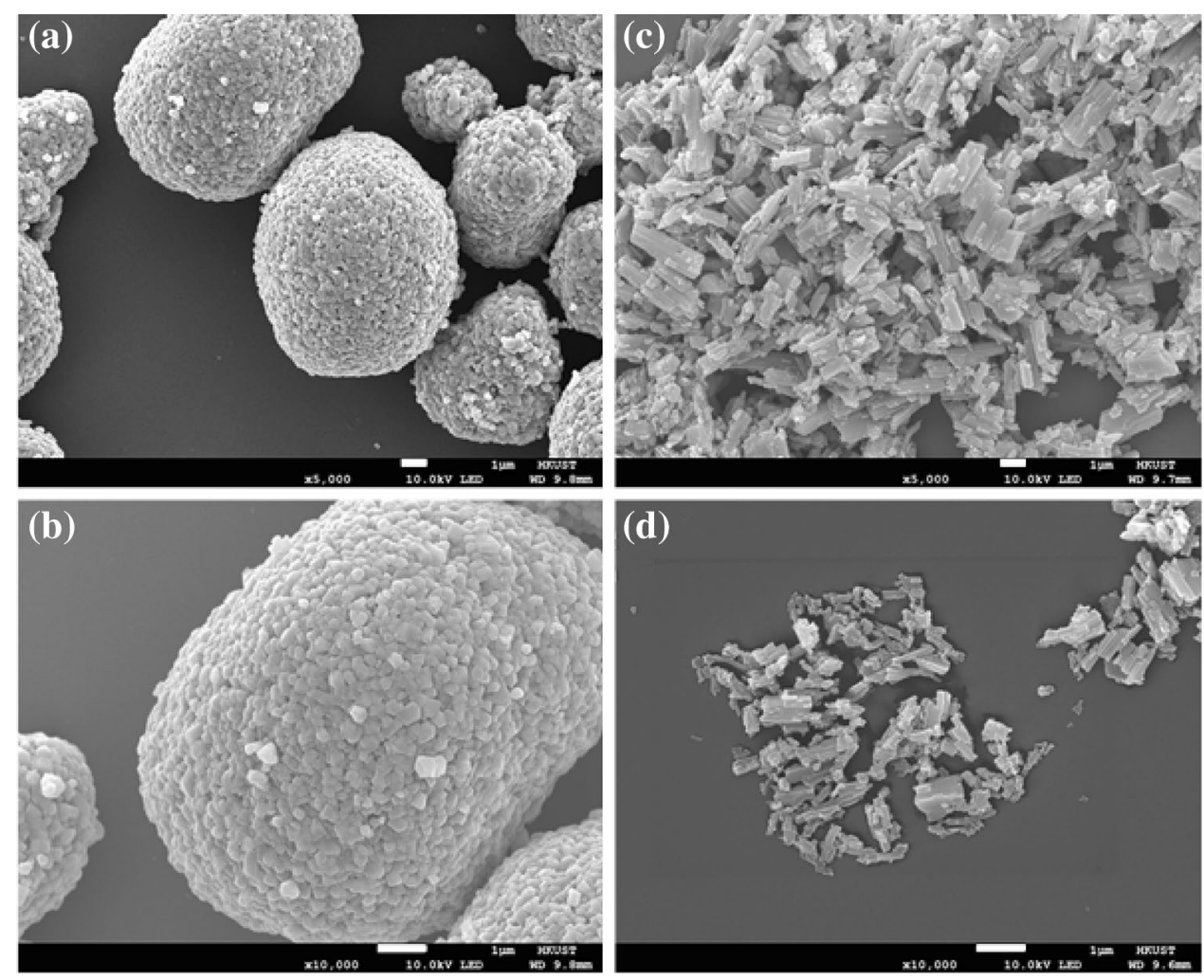

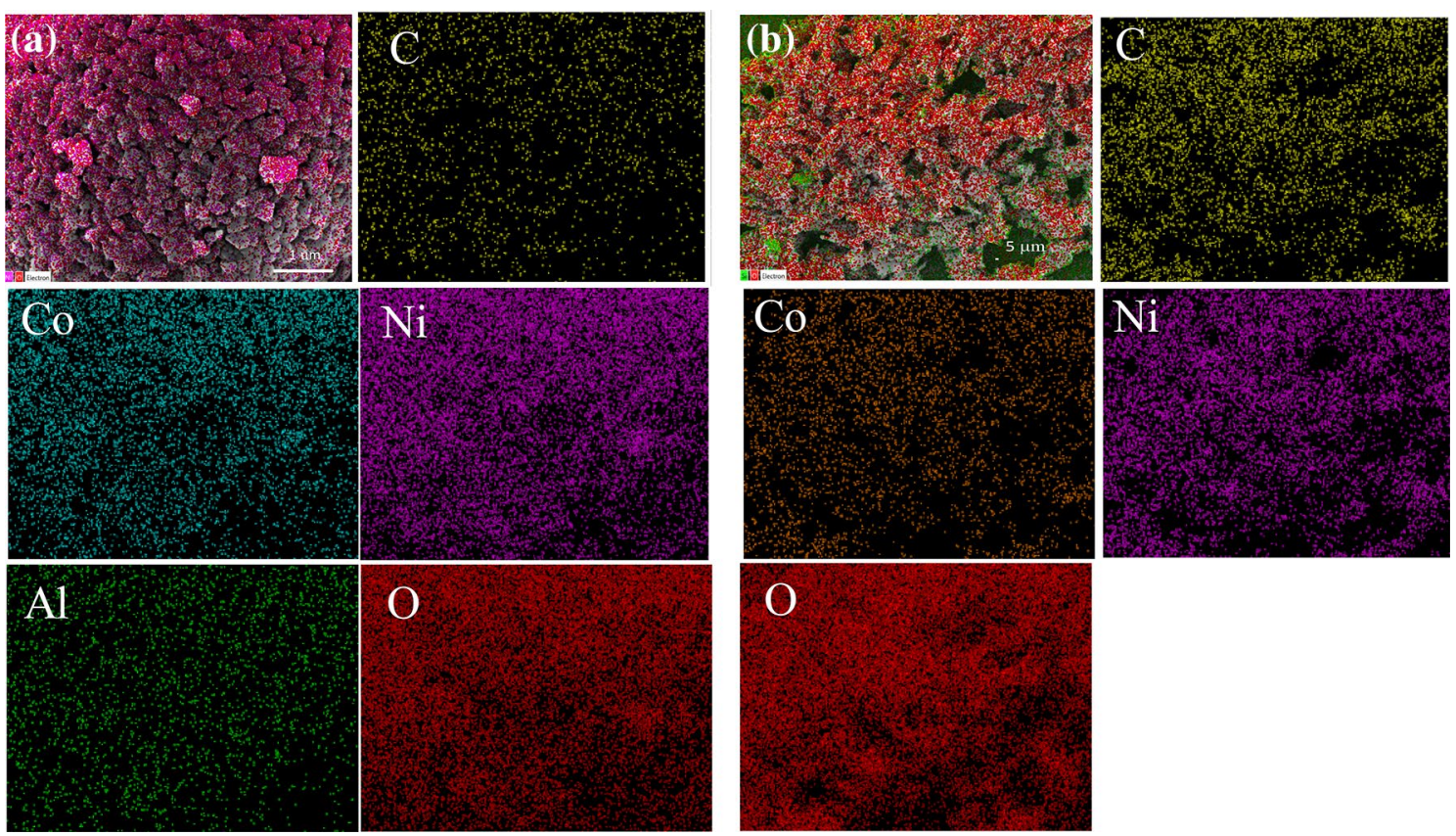

\section{$\mathrm{O}$}

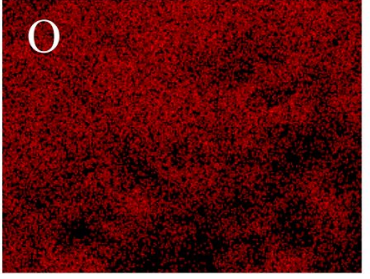

Fig. 4 EDX mapping of a cathode materials, $\mathbf{b}$ solid residue after selective dissolution

evenly distributed in the particles after dissolution, but no aluminum was detected.

The XRD data of the solid residue is shown in Fig. 5a, which indicates that mixed metals were present [21]. The presence of $\mathrm{Ni}$ and $\mathrm{Co}$ oxalates was further confirmed by ATR and TGA. Figure $5 \mathrm{~b}$ shows the ATR spectroscopic results of the solid residue. The bands at 1310 and $1359 \mathrm{~cm}^{-1}$ can be assigned to $\mathrm{O}-\mathrm{C}-\mathrm{O}$ symmetric stretching, and the band at $1610 \mathrm{~cm}^{-1}$ is the result of asymmetric stretching. The broadband at $3370 \mathrm{~cm}^{-1}$ is the fingerprint of hydration in the residue [22-25]. Figure $5 c$ shows the TGA results obtained for the solid residue in the air at a heating rate of $10 \mathrm{~K} / \mathrm{min}$. No weight loss was observed below $150^{\circ} \mathrm{C}$, implying that the powder had no free water. From 150 to $230^{\circ} \mathrm{C}$, the weight loss was about $19.5 \%$, which corresponded to the release of two structural
Fig. 5 a XRD patterns, b ATR results, and c TGA results of solid residue after oxalic acid dissolution (a)

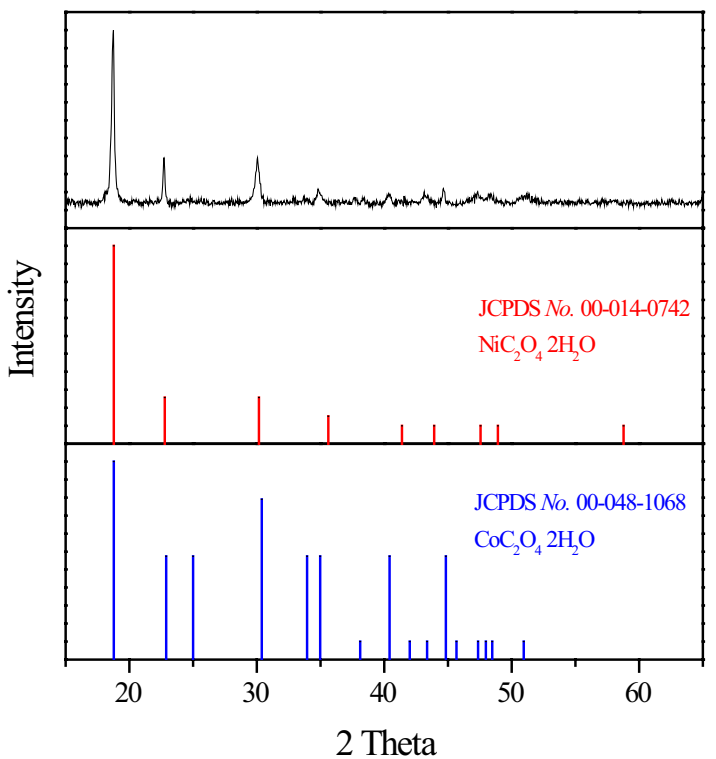

(b)

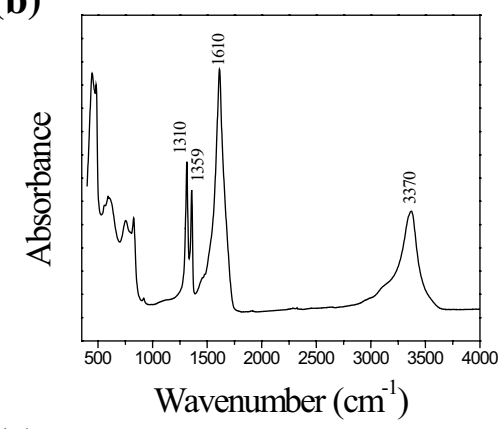

(c)

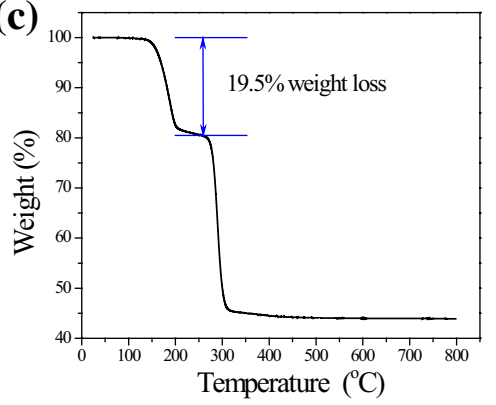

SN Applied Sciences A SPRINGER NATURE journa 
water molecules [26]. The weight loss matched well the theoretical value of $19.5 \%$ when $\mathrm{H}_{2} \mathrm{O}$ was released from a mixture of $\mathrm{NiC}_{2} \mathrm{O}_{4} \cdot 2 \mathrm{H}_{2} \mathrm{O}$, and $\mathrm{CoC}_{2} \mathrm{O}_{4} \cdot 2 \mathrm{H}_{2} \mathrm{O}$ in the ratio mentioned above. The second stage weight loss resulted from oxalate decomposition [27-29].

Taken together, it could be concluded that the liquid phase after selective lithium dissolution was made up of $\mathrm{Li}^{+}, \mathrm{Al}^{3+}, \mathrm{HC}_{2} \mathrm{O}_{4}^{-}$, and $\mathrm{H}_{2} \mathrm{C}_{2} \mathrm{O}_{4}$. The solid residue was a mixture of $\mathrm{CoC}_{2} \mathrm{O}_{4} \cdot 2 \mathrm{H}_{2} \mathrm{O}$ and $\mathrm{NiC}_{2} \mathrm{O}_{4} \cdot 2 \mathrm{H}_{2} \mathrm{O}$. The solution (stream 3) after selective dissolution contains 2370 ppm of $\mathrm{Li}^{+}$and $294 \mathrm{ppm}$ of $\mathrm{Al}^{3+}$.

\subsection{Aluminum removal (step 2)}

Since $\mathrm{K}_{2} \mathrm{C}_{2} \mathrm{O}_{4}$ has a higher solubility than $\mathrm{Na}_{2} \mathrm{C}_{2} \mathrm{O}_{4}$, and $\left(\mathrm{NH}_{4}\right)_{2} \mathrm{C}_{2} \mathrm{O}_{4}, \mathrm{KOH}$ was selected here as the precipitant. In addition, a concentration of $10 \mathrm{M}$ was used to minimize the dilution of the lithium in the solution, which would affect the lithium recovery afterwards. The results of aluminum removal are listed in Table 2 . By adding $0.4 \mathrm{~mL}$ of $10 \mathrm{M} \mathrm{KOH}, 77.8 \%$ of $\mathrm{Al}$ was precipitated as $\mathrm{Al}(\mathrm{OH})_{3}$. The recovery increased to $99.2 \%$ when $0.5 \mathrm{~mL}$ of $10 \mathrm{M} \mathrm{KOH}$

Table 2 Experimental results on aluminum removal by chemical precipitation $(10 \mathrm{~mL}$ feed)

\begin{tabular}{lllll}
\hline Precipitant & $\begin{array}{l}\text { The volume } \\
\text { of precipi- } \\
\text { tant }(\mathrm{mL})\end{array}$ & $\begin{array}{l}\mathrm{pH} \text { of the } \\
\text { solution } \\
\text { after pre- } \\
\text { cipitation }\end{array}$ & $\begin{array}{l}\text { The con- } \\
\text { centration } \\
\text { of Al in the } \\
\text { solution } \\
\text { (ppm) }\end{array}$ & $\begin{array}{l}\text { \% of Al pre- } \\
\text { cipitated as } \\
\text { solid (\%) }\end{array}$ \\
\hline $\mathrm{KOH}(10 \mathrm{M})$ & 0.4 & 9.37 & 65.4 & 77.8 \\
& 0.5 & 10.87 & 2.21 & 99.2 \\
& 0.6 & 12.54 & 137 & 53.5 \\
\hline
\end{tabular}

was used. More was not better. The recovery of Al would drop back to $53.5 \%$ by increasing the volume of $\mathrm{KOH}$ from $0.5 \mathrm{~mL}$ to $0.6 \mathrm{~mL}$. The reason can be understood from Fig. $\mathrm{S1}$, which was simulated using the Medusa software [30] and shows the relation between the solubility of different aluminum species and $\mathrm{pH}$. As the $\mathrm{pH}$ of the solution after the selective dissolution is around 1.6, aluminum was in the form of soluble complexes with oxalate ions. When the $\mathrm{pH}>12$, soluble $\mathrm{Al}(\mathrm{OH})_{4}^{-}$became the dominant species. At $0.6 \mathrm{~mL} \mathrm{KOH}$, the $\mathrm{pH}$ was 12.54 (Table 2).

\subsection{Lithium recovery (step 3)}

After the removal of $\mathrm{Al}$, the solution (stream 7) contained $\mathrm{Li}+, \mathrm{K}+, \mathrm{C}_{2} \mathrm{O}_{4}{ }^{2-}$, and $\mathrm{OH}^{-}$. Lithium was recovered by chemical precipitation using $\mathrm{K}_{2} \mathrm{CO}_{3}$ as the precipitant at an elevated temperature of $80^{\circ} \mathrm{C}$ [31]. By adding $4 \mathrm{~mL}$ of $5 \mathrm{M}$ $\mathrm{K}_{2} \mathrm{CO}_{3}$ solution to $20 \mathrm{~mL}$ of feed solution (stream 7), the concentration of lithium dropped from 2313 to 543 ppm, giving a lithium recovery of $76.5 \%$ as lithium carbonate. The XRD and SEM are shown in Fig. 6a and b, respectively, and the purity was checked by ICP, which is $>99.5 \%$.

\subsection{Acid baking of the mixed oxalates (step 4) and dissolution (step 5)}

The solid stream (stream 4) after selective dissolution contained $\mathrm{Co}$ and $\mathrm{Ni}$ to be separated. Thermal treatment could be used to process the oxalates. However, the products from the thermal decomposition of $\mathrm{NiC}_{2} \mathrm{O}_{4} \cdot 2 \mathrm{H}_{2} \mathrm{O}$ and $\mathrm{CoC}_{2} \mathrm{O}_{4} \cdot 2 \mathrm{H}_{2} \mathrm{O}$ [21], which are $\mathrm{NiO}$ and $\mathrm{Co}_{2} \mathrm{O}_{3}$, still need further processing. Instead, an oxidative, thermal treatment using sulfuric acid is used to convert the mixed oxalates to mixed sulfates following the chemical equation below:
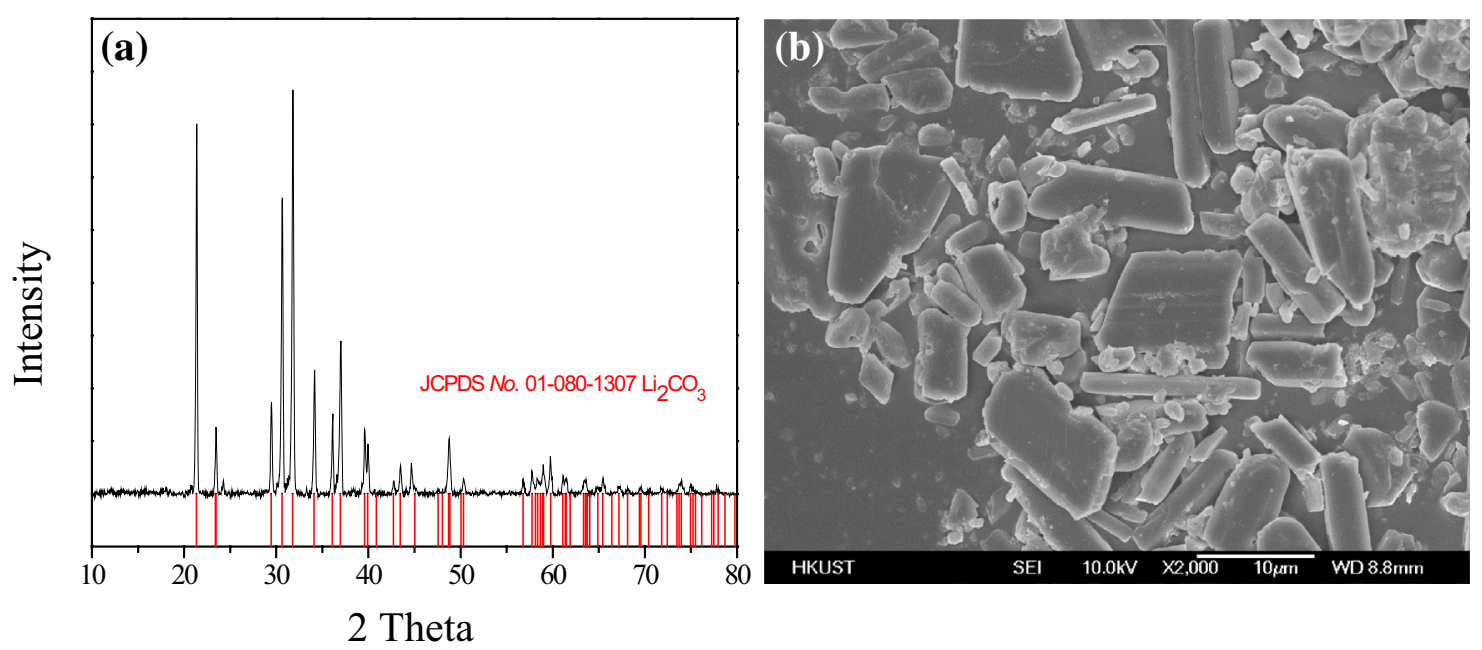

2 Theta

Fig. 6 a XRD patterns and $\mathbf{b}$ SEM photos of recovered $\mathrm{Li}_{2} \mathrm{CO}_{3}$ using $\mathrm{K}_{2} \mathrm{CO}_{3}$ as precipitant 
$\mathrm{MC}_{2} \mathrm{O}_{4}+2 \mathrm{H}_{2} \mathrm{SO}_{4} \rightarrow \mathrm{MSO}_{4}+2 \mathrm{CO}_{2}+\mathrm{SO}_{2}+2 \mathrm{H}_{2} \mathrm{O}(\mathrm{M}=\mathrm{Ni}$ and Co $)$

Sulfuric acid was selected over other mineral acids because at $337^{\circ} \mathrm{C}$ it has the highest boiling point. The amount of sulfuric acid was determined according to the stoichiometry ratio in Eq. 1. The reaction temperature was fixed at $300{ }^{\circ} \mathrm{C}$. The XRD patterns and SEM photo of the solids after thermal treatment is shown in Fig. 7. The XRD pattern of the solids matched well with that of pure $\mathrm{NiSO}_{4} \cdot 2 \mathrm{H}_{2} \mathrm{O}$, which is shown in Fig. $7 \mathrm{a}$. The morphology was changed from parallelepipedic to irregular particles, as revealed in Fig. 7b.

\subsection{Cobalt precipitation by oxidation (step 6)}

The separation of $\mathrm{Co}$ and $\mathrm{Ni}$ was achieved because of the difference in solubility of $\mathrm{Ni}(\mathrm{OH})_{2}(\mathrm{pKs}=14.2)$ and $\mathrm{Co}_{2} \mathrm{O}_{3}$ (pKs = 40.5) [4]. The feed was prepared by dissolving the mixed sulfates in an $\mathrm{S} / \mathrm{L}$ ratio of $50 \mathrm{~g} / \mathrm{L}$, giving an initial $\mathrm{pH}$ of 1.83 . $\mathrm{NaClO}$ was used as an oxidant to oxidize $\mathrm{Co}^{2+}$ to $\mathrm{Co}^{3+}[32]$. The reaction is shown below:

$2 \mathrm{Co}^{2+}+\mathrm{ClO}^{-}+2 \mathrm{H}_{2} \mathrm{O} \rightarrow \mathrm{Co}_{2} \mathrm{O}_{3}+4 \mathrm{H}^{+}+\mathrm{Cl}^{-}$

A series of experiments were conducted to investigate the effects of the molar ratio between $\mathrm{NaClO}$ and Co on the metal recovery of $\mathrm{Co}$ and $\mathrm{Ni}$, as shown in Fig. 8. As the amount of $\mathrm{NaClO}$ increased, the recovery of cobalt was increased from 37.23 to $92.2 \%$. Meanwhile $0.18 \%$ and $2.23 \%$ of nickel were co-precipitated at the same two ratios. As most of cobalt was precipitated, the remaining nickel in the solution can be recovered as $\mathrm{Ni}(\mathrm{OH})_{2}$ by adding $\mathrm{KOH}$.

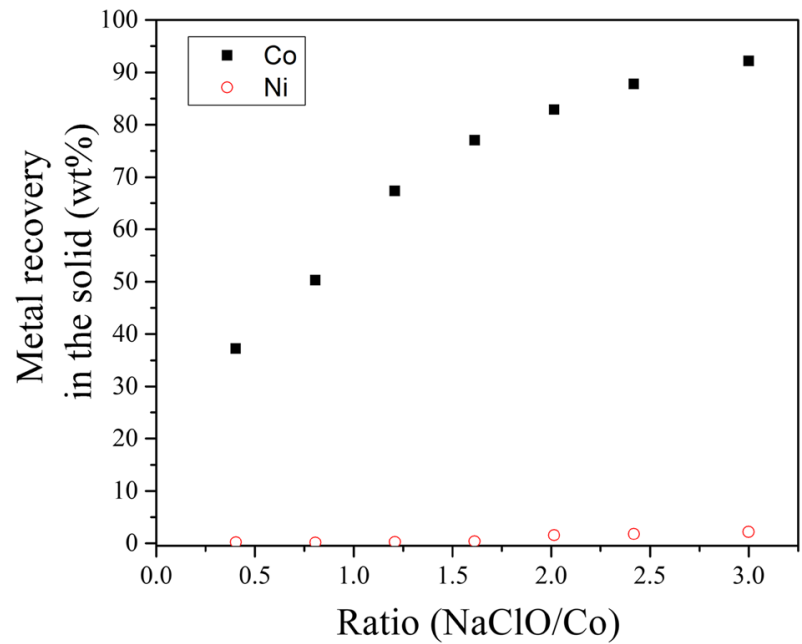

Fig. 8 Metal recovery in the solid after precipitation

\section{Conclusion}

A process to recover all the valuable metals from LNCA cathode materials was developed. In step 1, selective dissolution using oxalic acid was conducted. The conditions under which the maximum lithium and aluminum dissolved from the cathode materials were identified. Then, the $\mathrm{Al}^{3+}$ and $\mathrm{Li}^{+}$in the liquid stream were recovered separated by chemical precipitation in step 2 and step 3, using $\mathrm{KOH}$ and $\mathrm{K}_{2} \mathrm{CO}_{3}$, respectively. The solid mixture from step 1 underwent an acid baking treatment to produce a mixture of nickel and cobalt sulfates. The sulfate mixture was dissolved in water and then separated using $\mathrm{NaClO}$.

Cathode materials with relatively low aluminum concentration were used as the feed in this paper. If cathode on an aluminum foil is considered as the feed, the aluminum in the current collector would give a much higher
Fig. 7 a XRD patterns and $\mathbf{b}$ SEM photos of solid produced from acid baking
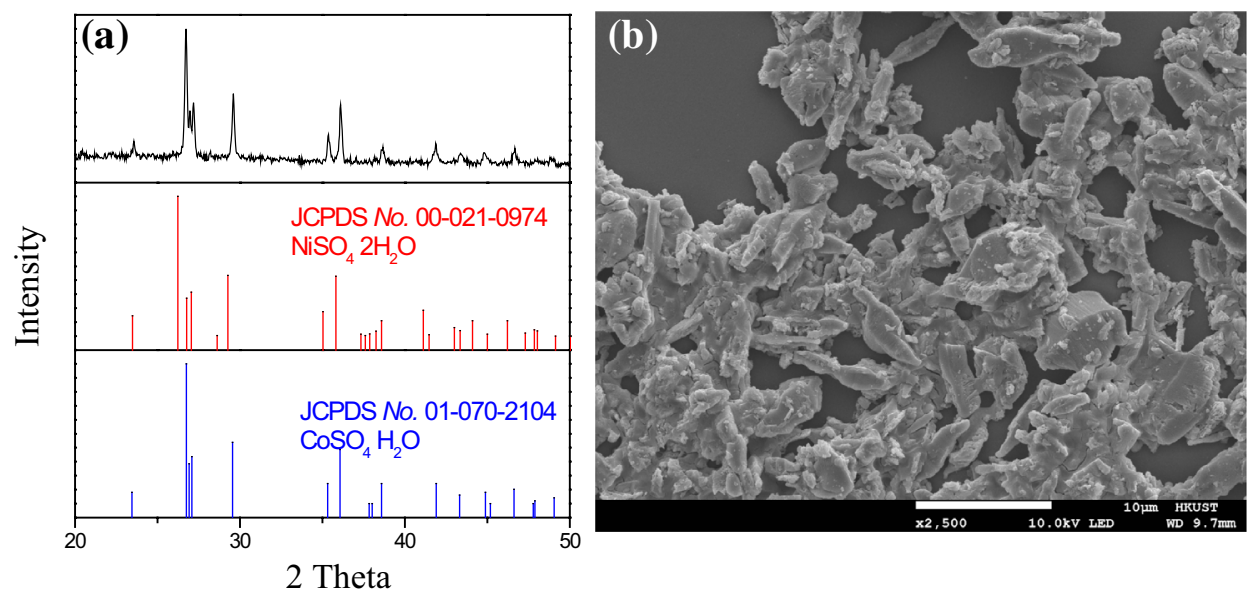
concentration of aluminum in the solution stream, which might lead to a formation of gel like $\mathrm{Al}(\mathrm{OH})_{3}$. Additional work still needs to be pursued to solve such issue.

\section{Compliance with ethical standards}

Conflict of interest The authors declare that they have no conflict of interest.

\section{References}

1. Jaskula BW (2018) Mineral commodity summaries 2018. U.S. Geological Survey, Reston

2. Palacin MR, de Guibert A (2016) Why do batteries fail? Science 351(6273):1253292. https://doi.org/10.1126/science.1253292

3. Chagnes A, Pospiech B (2013) A brief review on hydrometallurgical technologies for recycling spent lithium-ion batteries. J Chem Technol Biotechnol 88(7):1191-1199. https://doi. org/10.1002/jctb.4053

4. Joulié M, Laucournet R, Billy E (2014) Hydrometallurgical process for the recovery of high value metals from spent lithium nickel cobalt aluminum oxide based lithium-ion batteries. $J$ Power Sources 247:551-555. https://doi.org/10.1016/j.jpows our.2013.08.128

5. Zhang P, Yokoyama T, Itabashi O, Suzuki TM, Inoue K (1998) Hydrometallurgical process for recovery of metal values from spent lithium-ion secondary batteries. Hydrometallurgy 47(2):259-271. https://doi.org/10.1016/S0304-386X(97)00050-9

6. Castillo S, Ansart F, Laberty-Robert C, Portal J (2002) Advances in the recovering of spent lithium battery compounds. J Power Sources 112(1):247-254

7. Lee CK, Rhee K-I (2003) Reductive leaching of cathodic active materials from lithium ion battery wastes. Hydrometallurgy 68(1):5-10. https://doi.org/10.1016/S0304-386X(02)00167-6

8. Lee CK, Rhee K-I (2002) Preparation of LiCoO2 from spent lithium-ion batteries. J Power Sources 109(1):17-21

9. Zou H, Gratz E, Apelian D, Wang Y (2013) A novel method to recycle mixed cathode materials for lithium ion batteries. Green Chem 15(5):1183-1191. https://doi.org/10.1039/c3gc40182k

10. Ferreira DA, Prados LMZ, Majuste D, Mansur MB (2009) Hydrometallurgical separation of aluminium, cobalt, copper and lithium from spent Li-ion batteries. J Power Sources 187(1):238246. https://doi.org/10.1016/j.jpowsour.2008.10.077

11. Li L, Ge J, Wu F, Chen R, Chen S, Wu B (2010) Recovery of cobalt and lithium from spent lithium ion batteries using organic citric acid as leachant. J Hazard Mater 176(1):288-293

12. Li L, Qu W, Zhang X, Lu J, Chen R, Wu F, Amine K (2015) Succinic acid-based leaching system: a sustainable process for recovery of valuable metals from spent $\mathrm{Li}$-ion batteries. J Power Sources 282:544-551

13. Nayaka GP, Pai KV, Santhosh G, Manjanna J (2016) Dissolution of cathode active material of spent Li-ion batteries using tartaric acid and ascorbic acid mixture to recover Co. Hydrometallurgy 161:54-57. https://doi.org/10.1016/j.hydromet.2016.01.026

14. Cai G, Fung KY, Ng KM, Wibowo C (2014) Process development for the recycle of spent lithium ion batteries by chemical precipitation. Ind Eng Chem Res 53(47):18245-18259. https://doi. org/10.1021/ie5025326

15. Nan J, Han D, Zuo X (2005) Recovery of metal values from spent lithium-ion batteries with chemical deposition and solvent extraction. J Power Sources 152:278-284
16. Chen X, Kang D, Cao L, Li J, Zhou T, Ma H (2019) Separation and recovery of valuable metals from spent lithium ion batteries: simultaneous recovery of Li and Co in a single step. Sep Purif Technol 210:690-697. https://doi.org/10.1016/j.seppu r.2018.08.072

17. Sun L, Qiu K (2012) Organic oxalate as leachant and precipitant for the recovery of valuable metals from spent lithium-ion batteries. Waste Manag 32(8):1575-1582

18. Chen X, Fan B, Xu L, Zhou T, Kong J (2016) An atom-economic process for the recovery of high value-added metals from spent lithium-ion batteries. J Clean Prod 112:3562-3570. https://doi. org/10.1016/j.jclepro.2015.10.132

19. Li Q, Fung KY, Xu L, Wibowo C, Ng KM (2019) Process synthesis: selective recovery of lithium from lithium ion battery cathode materials. Ind Eng Chem Res 58(8):3118-3130. https://doi. org/10.1021/acs.iecr.8b04899

20. Li Q, Fung KY, Ng KM (2019) Separation of Ni, Co, and Mn from spent $\mathrm{LiNi}_{0.5} \mathrm{Mn}_{0.3} \mathrm{Co}_{0.2} \mathrm{O}_{2}$ cathode materials by ammonia dissolution. ACS Sustain Chem Eng (Revision submitted)

21. Wu HB, Pang H, Lou XW (2013) Facile synthesis of mesoporous $\mathrm{Ni} 0.3 \mathrm{C} 02.7 \mathrm{O} 4$ hierarchical structures for high-performance supercapacitors. Energy Environ Sci 6(12):3619-3626. https:// doi.org/10.1039/c3ee42101e

22. Edwards HGM, Hardman PH (1992) A vibrational spectroscopic study of cobalt (II) oxalate dihydrate and the dipotassium bisoxalatocobalt (II) complex. J Mol Struct 273:73-84

23. Bickley RI, Edwards HGM, Rose SJ (1991) A Raman spectroscopic study of nickel(II) oxalate dihydrate, $\mathrm{NiC}_{2} \mathrm{O}_{4} 2 \mathrm{H}_{2} \mathrm{O}$ and dipotassium bisoxalatonickel(II) hexahydrate, $\mathrm{K}_{2} \mathrm{Ni}\left(\mathrm{C}_{2} \mathrm{O}_{4}\right)_{2} 6 \mathrm{H}_{2} \mathrm{O}$. J Mol Struct 243(3):341-350. https://doi.org/10.1016/00222860(91)87048-M

24. Wang D, Belharouak I, Zhou G, Amine K (2013) Synthesis of lithium and manganese-rich cathode materials via an oxalate coprecipitation method. J Electrochem Soc 160(5):A3108-A3112

25. Mancilla N, Caliva V, D'Antonio MC, Gonzalez-Baro AC, Baran EJ (2009) Vibrational spectroscopic investigation of the hydrates of manganese (II) oxalate. J Raman Spectrosc 40(8):915-920

26. Donkova B, Mehandjiev D (2004) Mechanism of decomposition of manganese(II) oxalate dihydrate and manganese(II) oxalate trihydrate. Thermochim Acta 421(1):141-149. https:// doi.org/10.1016/j.tca.2004.04.001

27. Gao X, Dollimore D (1993) The thermal decomposition of oxalates: part 26. A kinetic study of the thermal decomposition of manganese(II) oxalate dihydrate. Thermochim Acta 215:47-63. https://doi.org/10.1016/0040-6031(93)80081-K

28. Allen JA, Scaife DE (1954) The thermal decomposition of nickel oxalate. J Phys Chem 58(8):667-671. https://doi.org/10.1021/ j150518a017

29. Mansour SAA (1994) Spectrothermal studies on the decomposition course of cobalt oxysalts Part III. Cobalt oxalate dihydrate. Mater Chem Phys 36(3):324-331. https://doi.org/10.1016/02540584(94)90049-3

30. Puigdomenech I (2016) Chemical equilibrium diagrams. https ://www.kth.se/che/medusa/downloads-1.386254. Accessed 22 Feb 2018

31. Swain B (2018) Cost effective recovery of lithium from lithium ion battery by reverse osmosis and precipitation: a perspective. J Chem Technol Biotechnol 93(2):311-319

32. Miller MJ, Scheithauer RA (1990) Method for separation of cobalt from nickel. Google Patents

Publisher's Note Springer Nature remains neutral with regard to jurisdictional claims in published maps and institutional affiliations. 